Cite this: J. Mater. Chem. A, 2014, 2 , 7054

Received 21st December 2013 Accepted 21st February 2014

DOI: 10.1039/c3ta15347a

www.rsc.org/MaterialsA

\section{Binary metal oxides for composite ultrafiltration membranes}

\author{
A. Sotto, ${ }^{a}$ J. Kim, ${ }^{\text {b }}$ J. M. Arsuaga, ${ }^{a}$ G. del Rosario, ${ }^{c}$ A. Martínez, ${ }^{d}$ D. Nam, ${ }^{b}$ P. Luis ${ }^{e}$ \\ and B. Van der Bruggen ${ }^{\star f}$
}

A new ultrafiltration membrane was developed by the incorporation of binary metal oxides of the type $\mathrm{Ti}_{(x)} \mathrm{Zr}_{(1-x)} \mathrm{O}_{2}$ inside polyethersulfone. Physico-chemical characterization of the binary metal oxides demonstrated that the presence of $\mathrm{Ti}$ in the $\mathrm{TiO}_{2}-\mathrm{ZrO}_{2}$ system results in an increase of the size of the oxides, and also their dispersity. The crystalline phases of the synthesized binary metal oxides were identified as srilankite and zirconium titanium oxide. The effect of the addition of $\mathrm{ZrO}_{2}$ can be expressed in terms of the inhibition of crystal growth of nanocrystalline $\mathrm{TiO}_{2}$ during the synthesis process. For photocatalytic applications the band gap of the synthesized semiconductors was determined, confirming a gradual increase (blue shift) in the band gap as the amount of $\mathrm{Zr}$ loading increases. Distinct distributions of binary metal oxides were found along the permeation axis for the synthesized membranes. Particles with Ti are more uniformly dispersed throughout the membrane cross-section. The physico-chemical characterization of membranes showed a strong correlation between some key membrane properties and the spatial particle distribution in the membrane structure. The proximity of metal oxide fillers to the membrane surface determines the hydrophilicity and porosity of modified membranes. Membranes incorporating binary metal oxides were found to be promising candidates for wastewater treatment by ultrafiltration, considering the observed improvement in flux and anti-fouling properties of doped membranes. Multi-run fouling tests of doped membranes confirmed the stability of permeation through membranes embedded with binary $\mathrm{TiO}_{2}-\mathrm{ZrO}_{2}$ particles.

\section{Introduction}

Ultrafiltration is today an established technology for water treatment, either for the purification of water from natural resources, pretreatment for seawater desalination or sewage treatment. ${ }^{1}$ Polyethersulfone, polysulfone and polyvinylidenefluoride are the most common polymers used for the fabrication of ultrafiltration membranes. ${ }^{2,3}$

Membrane fouling is considered one of the main drawbacks in the performance of ultrafiltration membranes, often related to hydrophobicity. The hydrophobic surface of ultrafiltration membranes depends on the hydrophobic nature of the

${ }^{a}$ Department of Chemical and Energy Technology, Rey Juan Carlos University, 28933-Móstoles, Madrid, Spain

${ }^{b}$ Department of Environmental Engineering, Inha University, 100, Inha-ro, Incheon, Republic of Korea

'Technological Support Center, Rey Juan Carlos University, 28933-Móstoles, Madrid, Spain

${ }^{d}$ Department of Basic Sciences Applied to Engineering, Technical University of Madrid, Madrid, Spain

${ }^{e}$ Materials and Process Engineering (iMMC-IMAP), Université Catholique de Louvain, Place Sainte Barbe 2, 1348 Louvain-la-Neuve, Belgium

${ }^{f}$ Department of Chemical Engineering, KU Leuven, W. de Croylaan 46, B-3001 Leuven, Belgium. E-mail: Bart.VanderBruggen@cit.kuleuven.be polymeric membrane surface. The fouling mechanism can be described in terms of adsorption, deposition or accumulation of foulants of organic chemical nature on the membrane surface. ${ }^{4,5}$ Adsorbed molecules increase the hydrophobicity of the membrane or may decrease the pore diameter, leading to a decline of water permeability. ${ }^{6}$ One of the methods proposed in the recent literature to avoid membrane fouling is the use of hydrophilic particles as additives to the membrane compositions. Due to the hydrophilic nature of additives immersed in the membrane structure, the undesired hydrophobic interactions that take place between organic foulants and the membrane surface can be reduced considerably. Enhanced membranes with better anti-fouling properties lead to an improved performance in terms of permeability, solute rejection, or membrane lifetime. Many types of inorganic fillers have been proposed as polymeric membrane nanofillers. In the first place, $\mathrm{TiO}_{2}{ }^{7-11}$ is undoubtedly the preferred material for this goal, but also silica $\left(\mathrm{SiO}_{2}\right),{ }^{12,13}$ carbon nanotubes, ${ }^{14}$ zeolites, ${ }^{15,16}$ alumina $\left(\mathrm{Al}_{2} \mathrm{O}_{3}\right),{ }^{17}$ silver $(\mathrm{Ag}),{ }^{18}$ zirconia $\left(\mathrm{ZrO}_{2}\right),{ }^{19}$ zinc oxide $(\mathrm{ZnO})^{20}$ and zerovalent iron $(\mathrm{FeO})^{21}$ are of potential interest in this field.

The main focus is on the use of transition metal oxides to manufacture ultrafiltration membranes with a more hydrophilic character. As the membrane hydrophilicity increases, the 
adverse hydrophobic interactions that lead to the formation of a fouling layer are mitigated. ${ }^{22}$ Transition metal oxides have a wide variety of surface structures, which determine their elevated surface energy and hence their outspoken hydrophilic nature. ${ }^{23,24}$ Other significant approaches to improve the hydrophilicity of ultrafiltration membranes have been proposed, including the self-segregation of hydrophilic polymers and binding of nanoparticles to the membrane surface. ${ }^{25,26}$ In general, the incorporation of hydrophilic materials inside the membrane structure promotes the formation of membranes with a more open structure, with a higher average pore size and porosity, and with enhanced hydrophilicity. Both effects facilitate water transport through the membrane structure, thus increasing the membrane's water permeability. ${ }^{27}$ However, the use of metal oxides as nanofillers in membranes has some drawbacks. For example, high concentrations of metal oxide particles may lead to negative effects instead of an improvement, especially with respect to water permeability. ${ }^{28}$

Furthermore, a disproportionate increase of the membrane pore size provokes a non-equitable tradeoff between permeability and selectivity affecting negatively the general performance of the membrane. ${ }^{29}$ Another important concern is the environmental risk associated with the use of nanomaterials and the integrity of membrane functions. ${ }^{7}$

The influence of some properties, such as the particle size and especially its spatial particle distribution on the membrane performance, has not been studied yet. In this context, it is important to cite the studies reported by Maximous et al. These authors showed the influence of the distribution pattern of $\mathrm{Al}_{2} \mathrm{O}_{3}$ and $\mathrm{ZrO}_{2}$ particles on the performance of polyethersulfone modified membranes. ${ }^{30,31}$ Recently, Sotto et al. suggested that it is possible to reach a noteworthy enhancement in the permeability and membrane anti-fouling properties for an unusually low range of $\mathrm{TiO}_{2}$ concentrations (below $0.4 \mathrm{wt}$ \%). ${ }^{32}$ Following this approach, Arsuaga et al. used low concentrations $(0.4 \mathrm{wt} \%)$ of $\mathrm{TiO}_{2}, \mathrm{ZrO}_{2}$ and $\mathrm{Al}_{2} \mathrm{O}_{3}$ as hydrophilic particles, and observed that the particle density of single metal oxides in the vicinity of the membrane surface affects positively the pore formation and prevents the decrease of permeate flux as a result of the deposition/adsorption of BSA molecules on the membrane's upper layer. ${ }^{33}$ The objective of this work is to prepare and characterize a new class of composite membranes applied to wastewater treatment, for which binary oxide metals have been synthesized in different stoichiometric combinations of $\mathrm{TiO}_{2}$ and $\mathrm{ZrO}_{2}$ in order to produce membranes with different permeation characteristics. In this work the influence of physico-chemical properties of the particles and their spatial distribution inside the membrane structure on the morphology and performance of new binary metal oxide doped membranes has been explored.

\section{Experimental}

\subsection{Materials}

Polyethersulfone (PES, $58 \mathrm{kDa}$ ) provided by BASF Co. (Germany) was used for preparation of polymeric membranes. This polymer was dried at $110^{\circ} \mathrm{C}$ in an oven overnight prior to use for the casting solution preparation. PES was dissolved in 1-methyl-2pyrrolidone (NMP, 99.5\%) solvent purchased from Sigma Chemical Co. Ltd (St Louis, USA). The non-woven support layer Viledon FO2471 was obtained from Freudenberg (Weinheim, Germany). As the model organic foulant Bovine Serum Albumin (BSA) purchased from Sigma-Aldrich (St Louis, MO) was selected. Milli-Q water was used as the solvent for preparation of BSA solutions ( $\left.1 \mathrm{~g} \mathrm{~L} \mathrm{~L}^{-1}, \mathrm{pH} 7.0\right)$ using $0.2 \mathrm{M}$ phosphate as a buffer solution.

\subsection{Synthesis and characterization of metal oxide particles}

Composite $\mathrm{TiO}_{2}-\mathrm{ZrO}_{2}$ nanoparticles were prepared by the solgel process described by Nghiem et al. ${ }^{22}$ and Mane et al. ${ }^{23}$ Titanium(Iv) isopropoxide (TIPP), Ti $\left[\mathrm{OCH}\left(\mathrm{CH}_{3}\right)_{2}\right]_{4}$, and zirconium(Iv) propoxide (ZPP), $\mathrm{Zr}\left(\mathrm{OCH}_{2} \mathrm{CH}_{2} \mathrm{CH}_{3}\right)_{4}$, were purchased as pure grade reagents (Junsei Inc., Japan) and used to synthesize composite $\mathrm{TiO}_{2}-\mathrm{ZrO}_{2}$ nanoparticles. The content of each precursor to prepare colloidal solutions was varied as follows: $0.01 \mathrm{~mol} \mathrm{~L}^{-1}(\mathrm{M}) \mathrm{TIPP}+0 \mathrm{M} \mathrm{ZPP}, 0.02 \mathrm{M} \mathrm{TIPP}+0.01 \mathrm{M} \mathrm{ZPP}, 0.01$ $\mathrm{M}$ TIPP + 0.01 M ZPP, $0.01 \mathrm{M}$ TIPP + 0.02 M ZPP and $0 \mathrm{M}$ TIPP + $0.01 \mathrm{M}$ ZPP. This molar ratio corresponds to $0,33,50,67$ and $100 \mathrm{~mol} \%$ zirconia in $\mathrm{TiO}_{2}-\mathrm{ZrO}_{2}$ particles, respectively. Prepared solutions containing the desired molar ratio of TIPP and ZPP as precursors were placed into de-ionized (DI) water. Subsequently, this mixture was sonicated for 30 minutes and then stirred by using a magnetic stirrer for 24 hours at room temperature. After that, the solution was kept for 24 hours at room temperature and then dried for another 6 hours at $100{ }^{\circ} \mathrm{C}$ in a dry oven. The dried solution was calcined at $550{ }^{\circ} \mathrm{C}$ for 2 hours and the resulting powder was ground to yield composite $\mathrm{TiO}_{2}-\mathrm{ZrO}_{2}$ metal oxide particles. Particle grinding was performed using a McCrone Micronising mill device (Glen Creston, UK) that reduces samples to sub-micron sizes.

The crystal structure of the samples was studied by XRD measurements by using a Philips X-PERT MPD diffractometer ( $\mathrm{Cu} \mathrm{K} \alpha$ radiation) with a step size and counting time of $0.02^{\circ}$ and $10 \mathrm{~s}$, respectively. Appropriate sample preparation to obtain well-dispersed, isolated particles was accomplished. Metal oxide particles dispersed in ethanol were sonicated by ultrasound irradiation for $30 \mathrm{~min}$. Structural characterization was carried out by transmission electron microscopy (TEM) on a PHILIPS TECNAI-20 electron microscope operating at $200 \mathrm{kV}$.

The $\mathrm{TiO}_{2}$ and $\mathrm{ZrO}_{2}$ molar concentrations of the samples were determined by inductively coupled plasma spectroscopy (ICP) with a VARIAN VISTA AX apparatus. The percentage of UV-vis reflectance of powder samples was measured by diffuse reflectance spectroscopy using a Varian Cary 500 Scan UV-vis-NIR spectrophotometer (integrating sphere) instrument.

\subsection{Membrane preparation}

Neat (membrane 0) and modified (membranes A-E) PES membranes were synthesized by immersion precipitation. Prior to the preparation of modified membranes, the metal oxide fillers $(0.5 \mathrm{~g})$ were dispersed in a corresponding volume of NMP for 5 hours by mechanical stirring and ultrasound sonication. Once the uniform dispersion of added particles in NMP was 
achieved, $20 \mathrm{~g}$ of polymer was added to form $100 \mathrm{~g}$ of metal oxide/polymeric solution. The polymer film of PES cast at $20 \mathrm{wt} \%$ in NMP was immersed in a non-solvent bath of distilled water, in which phase separation occurs to form the membrane. The membrane was afterwards repeatedly washed with distilled water to remove the remaining solvent, and stored wet. In order to estimate the average value of measured variables in this investigation, four identical membrane sheets were prepared and tested.

\subsection{Membrane characterization}

Contact angle measurements were performed with a KSV CAM 200 instrument (KSV Instruments, USA) using the sessile drop technique. Scanning Electron Microscopy (SEM, XL-30, Philips, Eindhoven, the Netherlands) equipment was used to study the morphology of the cross-section of the membranes. In order to obtain the distribution pattern of metal oxides in the membrane cross-section, an energy dispersive spectrometer was coupled to SEM technology. For this analysis the samples were explored without application of a conductive metal coating procedure. Due to the requirements of image magnification to determine the membrane pore size distribution, a Field Emission Gun Scanning Electron Microscope (FEG-SEM, FEI, the Netherlands) was used. Four samples of each type of doped membranes were analyzed to estimate the statistical distribution, calculated in ponder percentage, as a ratio of the number of particles confined to a specific area to the total number of particles distributed along the membrane structure in the crosssection area analyzed.

Water uptake tests were conducted to evaluate the adsorption of water by the composite membranes in order to determine the overall membrane porosity $\left(P_{\mathrm{r}} \%\right)$, using the following equation:

$$
P_{\mathrm{r}}(\%)=\left(\frac{W_{\mathrm{w}}-W_{\mathrm{d}}}{S d \rho}\right) \times 100
$$

where $W_{\mathrm{w}}$ and $W_{\mathrm{d}}$ are the weights of the membrane at equilibrium, wetted and dried; $S$ is the membrane area; $d$ is the thickness and $\rho$ is the density of water. Average values of membrane porosity were calculated from measurements taken for 4 samples of each membrane.

\subsection{Ultrafiltration procedure}

The performance of neat and modified membranes was explored in terms of pure water flux, fouling performance and solute rejection studies using a cross-flow filtration setup. ${ }^{5}$ The ultrafiltration device and the experimental procedure followed in this study are similar to the previous work. ${ }^{31}$ The experiments were carried out in recycle mode at 2 bar trans-membrane pressure and $25{ }^{\circ} \mathrm{C}$. For pure water permeation experiments, the feed was left to circulate for a period typically of $2 \mathrm{~h}$, whereas for the BSA model solution the experimental time was around $12 \mathrm{~h}$ from the solution introduction before starting the sampling of permeate and feed.

A Varian Cary 500 Scan UV-vis-NIR spectrophotometer was used to determine the solute concentration for permeate and feed samples containing BSA in Milli-Q water. The rejection was calculated by:

$$
R(\%)=\left(1-\frac{C_{\mathrm{p}}}{C_{\mathrm{f}}}\right) \times 100
$$

where $C_{\mathrm{p}}$ and $C_{\mathrm{f}}$ are the permeate and feed concentrations of PEG, respectively.

To describe flux decline, the water flux is defined as a function of transmembrane pressure $(\Delta P)$, viscosity $(\eta)$ and total membrane resistance $\left(R_{\mathrm{t}}\right)$ :

$$
J=\frac{\Delta P}{\eta R_{\mathrm{t}}}
$$

\section{Results and discussion}

\subsection{Characterization of binary oxide $\operatorname{Ti}_{(x)} \operatorname{Zr}_{(1-x)} \mathbf{O}_{2}$ particles}

The composition of synthesized metal oxides investigated by ICP was similar to the theoretically expected values of molar percentages of $\mathrm{TiO}_{2}$ and $\mathrm{ZrO}_{2}$ in the binary oxides (Table 1). ICP measurements strictly yield the metal weight percentages ( $\mathrm{Ti}$ and $\mathrm{Zr}$ ). Values shown in Table 1 were calculated by assuming stoichiometric oxide compositions $\left(\mathrm{TiO}_{2}\right.$ and $\left.\mathrm{ZrO}_{2}\right)$.

The X-ray powder diffraction patterns of synthesized binary metal oxides investigated in this study are shown in Fig. 1.

The crystalline phases of the synthesized metal oxides A-E were identified as shown in Table 2. The crystal phase recognition procedure was accomplished by combining the XRD experiments (Fig. 1) with high-resolution transmission electron microscopy (HRTEM) imaging. In Fig. 2, the digital diffraction pattern (DDP) obtained from the polycrystals is shown as the inset.

The observed diffraction patterns suggest the existence of a periodic arrangement of atoms conforming to different sets of atomic planes. Based on the information provided by the geometry of the diffraction directions, the crystal system can be recognized. In addition, the intensities of the diffracted rays are related to the nature of the atoms and the positions occupied in the crystal lattice, so that their measurement is a method for obtaining three-dimensional information about the internal crystal structure.

Considering the XRD measurements shown in Fig. 1 the most intense peaks corresponding to every powder sample can be recognized. Synthesized $\mathrm{TiO}_{2}$ (powder A) occurs as aggregates of nano-crystals in a predominant anatase phase (Fig. 2 and 5). Its distinctive peaks appear at 20:25.31, 48.08, and

Table 1 Theoretical and ICP-mass measured values in mol\% of pure $\mathrm{TiO}_{2}$ and $\mathrm{ZrO}_{2}$ present in $\mathrm{Ti}_{(x)} \mathrm{Zr}_{(1-x)} \mathrm{O}_{2}$ binary metal oxides

\begin{tabular}{lccccc}
\hline & \multicolumn{2}{l}{ Expected } & & \multicolumn{2}{l}{ Measured (ICP) } \\
\cline { 2 - 3 } \cline { 5 - 6 } Metal oxide & $\mathrm{TiO}_{2}(\%)$ & $\mathrm{ZrO}_{2}(\%)$ & & $\mathrm{TiO}_{2}(\%)$ & $\mathrm{ZrO}_{2}(\%)$ \\
\hline $\mathrm{A}$ & 100 & 0 & & 98 & 0 \\
$\mathrm{~B}$ & 67 & 33 & & 66 & 34 \\
$\mathrm{C}$ & 50 & 50 & & 53 & 57 \\
$\mathrm{D}$ & 33 & 67 & & 35 & 65 \\
E & 0.0 & 100 & & 0 & 96
\end{tabular}




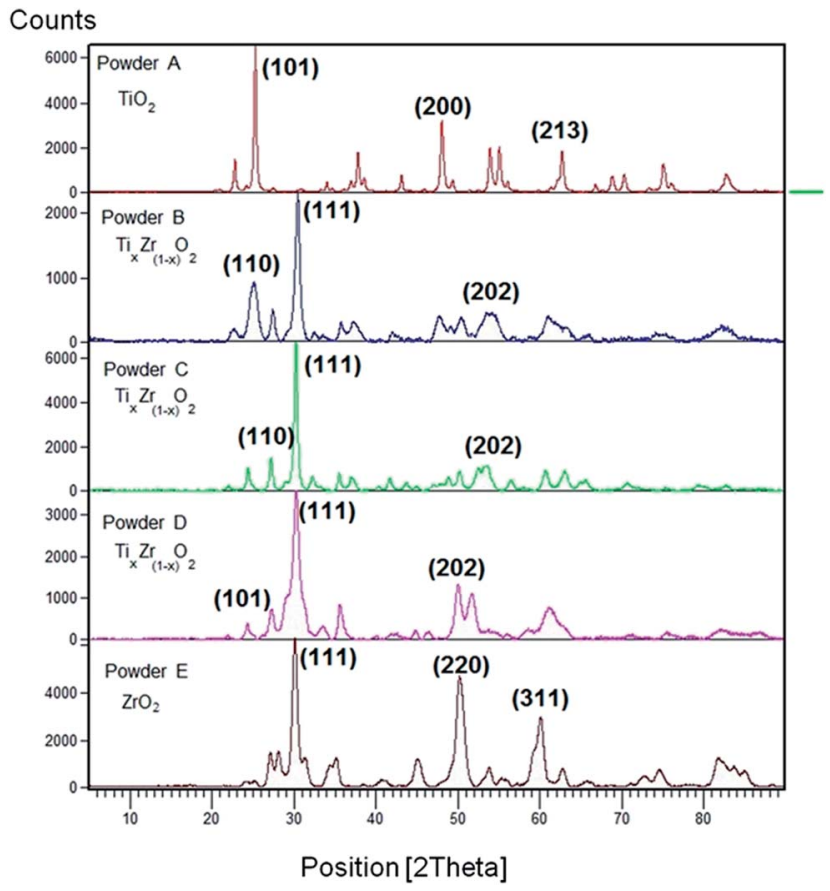

Fig. 1 XRD patterns of pure $\mathrm{TiO}_{2}$ and $\mathrm{ZrO}_{2}$ and $\mathrm{TiO}_{2}-\mathrm{ZrO}_{2}$ binary oxide powders. (A) $\mathrm{TiO}_{2}$, (B) $\mathrm{TiO}_{2}(67 \%)-\mathrm{ZrO}_{2}(33 \%)$, (C) $\mathrm{TiO}_{2}(50 \%)-$ $\mathrm{ZrO}_{2}(50 \%)$, (D) $\mathrm{TiO}_{2}(33 \%)-\mathrm{ZrO}_{2}(67 \%)$ and (E) $\mathrm{ZrO}_{2}$.

62.69, which correspond to the diffraction planes of $\left(\begin{array}{lll}1 & 0 & 1\end{array}\right),(2$ $\left.0 \begin{array}{ll}0\end{array}\right)$ and $\left(\begin{array}{lll}2 & 1 & 3\end{array}\right)$ Miller indices, respectively. For the zirconia sample (powder E), the predominant monoclinic phase of the $\mathrm{ZrO}_{2}$ micro-crystals was observed, which is in agreement with the literature. ${ }^{34}$ The monoclinic phase is obtained as a result of hydrolysis of the precursor of $\mathrm{ZrO}_{2}$. These results are in good agreement with the literature. ${ }^{35,36}$ In the binary metal oxides

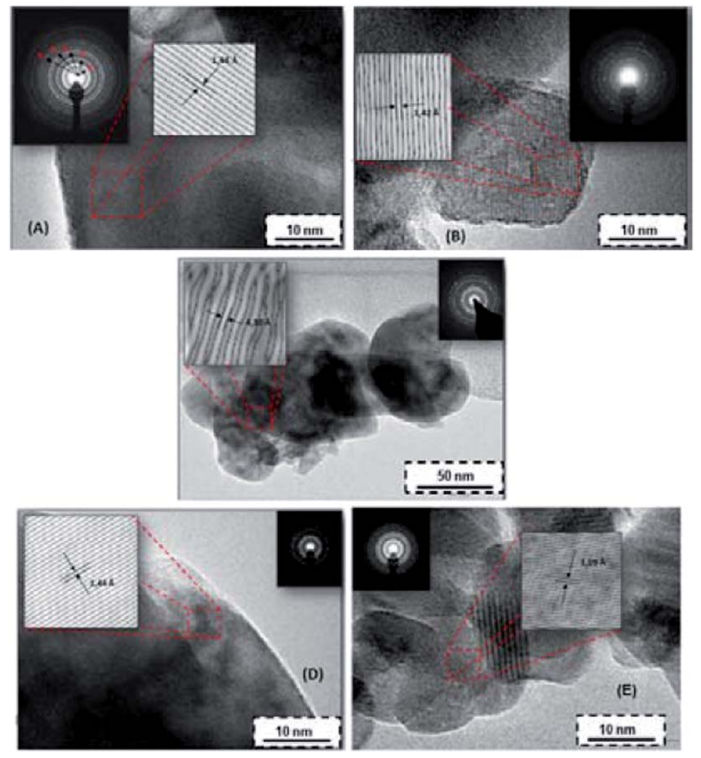

Fig. 2 HRTEM images of samples. The insets in the images are the digital diffraction patterns and the image processing for $d_{\mathrm{hkl}}$ determination from the corresponding particles. (A) $\mathrm{TiO}_{2}$, (B) $\mathrm{TiO}_{2}(67 \%)-$ $\mathrm{ZrO}_{2}(33 \%)$, (C) $\mathrm{TiO}_{2}(50 \%)-\mathrm{ZrO}_{2}(50 \%)$, (D) $\mathrm{TiO}_{2}(33 \%)-\mathrm{ZrO}_{2}(67 \%)$ and (E) $\mathrm{ZrO}_{2}$.

(powder B-D) highly crystalline particles still occur. Only several weak peaks of $\mathrm{TiO}_{2}$ are present in the XRD pattern of $\mathrm{Ti}_{(x)} \operatorname{Zr}_{(1-x)} \mathrm{O}_{2}$ samples. In agreement with the results shown in Fig. 2 the binary metal oxides mostly exist in the form of $\mathrm{ZrO}_{2}$ micro-crystals. The $\mathrm{ZrO}_{2}$ contribution inhibits the formation of $\mathrm{TiO}_{2}$ crystalline particles.

Unfortunately, detailed phase diagrams for the calcinated samples of $\mathrm{TiO}_{2}-\mathrm{ZrO}_{2}$ at relatively low temperatures are not

Table 2 Crystal phase identification values for the synthesized metal oxides

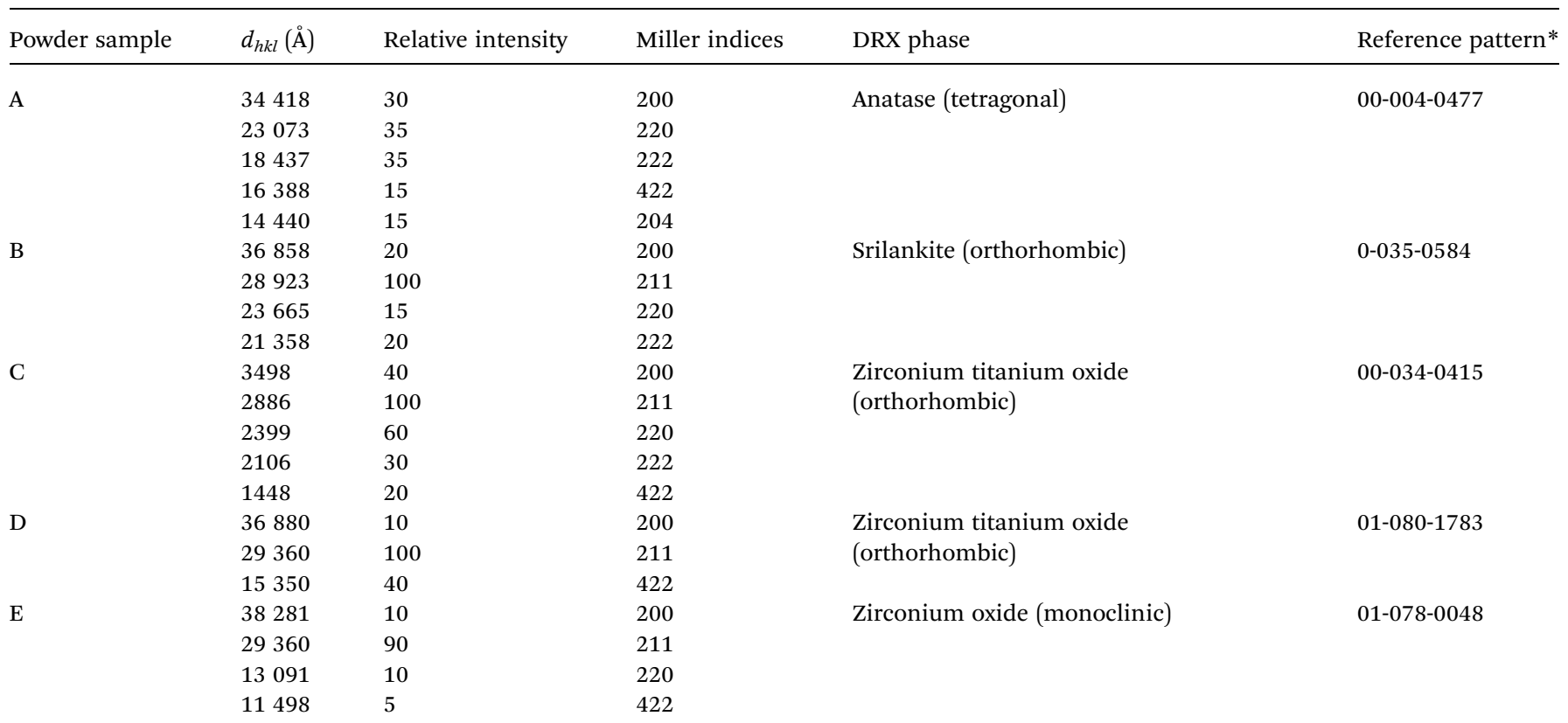


available in the literature. Troitzsch et $a .^{37}$ reported that as a result of slow kinetics of synthesis experiments performed at temperatures below $1200{ }^{\circ} \mathrm{C}$ the composition of these samples results in metastable phases in the $\mathrm{TiO}_{2}-\mathrm{ZrO}_{2}$ system. The solgel method, used in this study (calcination temperature $550{ }^{\circ} \mathrm{C}$ ), is prone to such effects, so that the equilibrium state of those samples is uncertain. ${ }^{38,39}$

Considering the possible presence of a combination of phases described as $\operatorname{Ti}_{(x)} \operatorname{Zr}_{(1-x)} \mathrm{O}_{2}$, the analysis and identification of the major phases from the diffraction patterns (Fig. 2) of these powders were accomplished. For this purpose, the spacing between the individual planes $d_{h k l}$ was measured using an image digital processor (Digital-Micrograph 3.6) from every digital diffraction pattern (DDP). Subsequently, Miller indices were calculated. ${ }^{38}$ Once the Miller indices are known, the identified phases by XRD are corroborated with the reference patterns summarized in the database.$^{43,44}$ Srilankite, a mineral with the chemical formula $\mathrm{Zr}_{2.20} \mathrm{Ti}_{1.80} \mathrm{O}_{8.00}$, was found to be the most probable crystalline phase for the powder B, synthesized at lower contents of $\mathrm{TiO}_{2}$, whereas zirconium titanium oxide chemically described as $\mathrm{ZrTiO}_{4}$ appears to be the predominant phase as a result of the increasing $\mathrm{Zr}$ content. Both chemical species yield adequate information about the crystal structure of $\mathrm{TiO}_{2}-\mathrm{ZrO}_{2}$ samples synthesized in this work.

Surface physico-chemical properties are relevant characteristics of the metal oxide particles. For this reason, hydrophilicity and zeta potential of metal oxides were evaluated. In all studied cases the observed contact angles were lower than $10^{\circ}$, suggesting a great hydrophilic character for the synthesized materials that could enhance the water permeation properties of doped membranes.

The zeta potential of the synthesized particles was measured for an aqueous solution containing $0.5 \mathrm{wt} \%$ of metal oxide at different pHs. Fig. 3 shows a typical amphoteric behavior of the electrophoretic mobility of metal oxide particles as a function of solution $\mathrm{pH}$, indicating that particles have a lower tendency to agglomerate when they are electrically charged. Solution $\mathrm{pH}$ affects the hydrodynamic diameter of particles by changing the particle surface charge and zeta potential. $\mathrm{TiO}_{2}$ particles show a higher dimension with average sizes around $3 \mu \mathrm{m}$. Agglomeration of metal oxide particles can dominate when the solution $\mathrm{pH}(\mathrm{ca} .6)$ is close to the isoelectric point because the repulsive force between particles caused by electrostatic interaction can be mitigated. ${ }^{32}$

Assuming that these metal oxides are used as semiconductors in different applications (e.g., as catalysts for water treatment, due to the high oxidation power ${ }^{42}$ ), the band gap energy of these materials was determined as a measure of their electric conductivity. As shown in Fig. 4, a gradual increase (blue shift) in the band gap is seen with an increase in the amount of $\mathrm{Zr}$ loadings. The band gap of the binary oxide samples was quite similar, indicating that their photoabsorbance properties are poorly related to their different compositions. The presence of $\mathrm{Ti}$, even at low contents, determined the conductivity of synthesized binary metal oxides. ${ }^{40}$

In order to evaluate the morphology (size and shape) of individual particles, TEM images of synthesized powders were
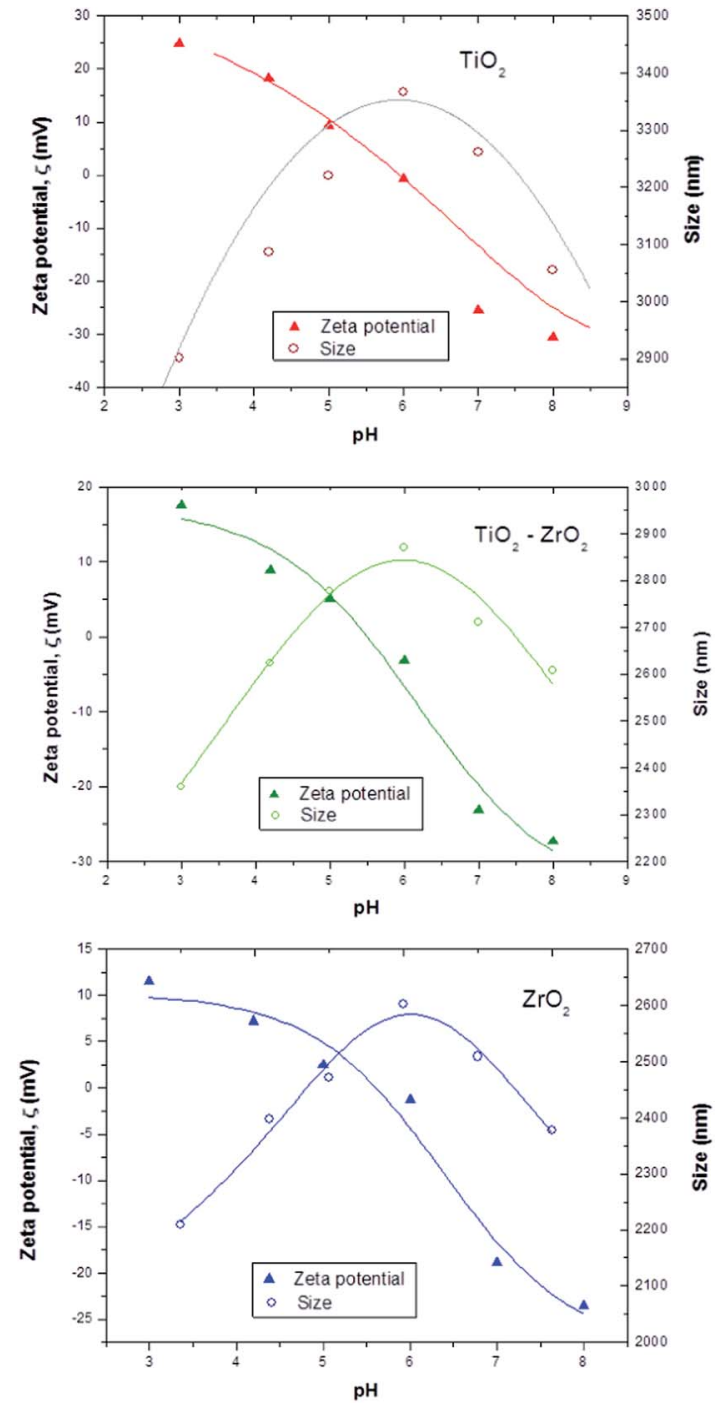

Fig. 3 Zeta potential (triangles) and average size (circles) of metal oxide particles as a function of aqueous solution $\mathrm{pH}$.

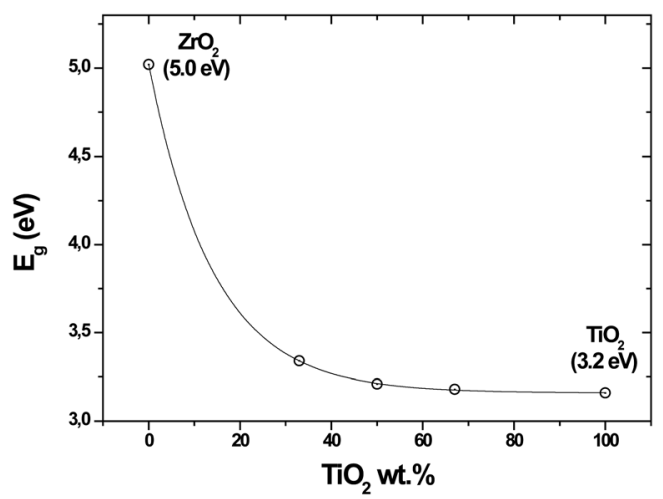

Fig. 4 Band gap energy of the synthesized metal oxides derived from the diffuse reflectance measurements.

taken. Fig. 5 shows the synthesized binary oxides as microparticles formed by aggregation of semi-spherical nanosized crystals with polyhedral shape and with different particle size 

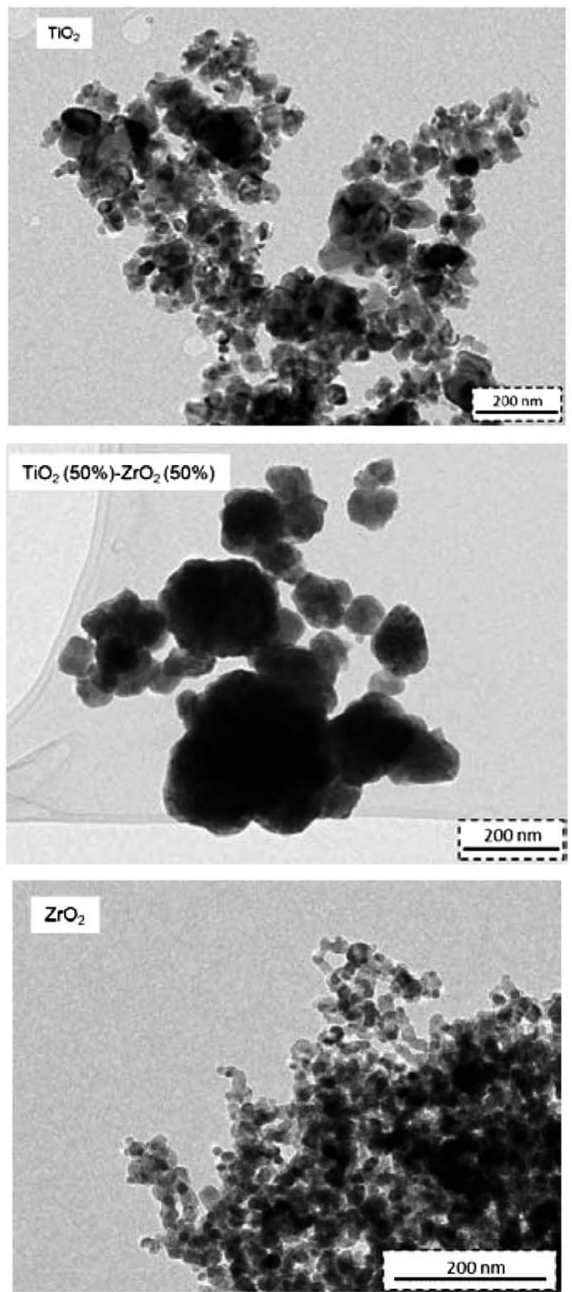

Fig. 5 TEM images of synthesized metal oxides.

distributions as a result of their composition. Table 3 summarizes some relevant size characteristics of individual nanoparticles. It can be seen that the incorporation of $\mathrm{TiO}_{2}$ into the general composition of synthesized metal oxides increases the individual particle size and at the same time the dispersion rate also increases, considering the standard deviation values.

In general, all analyzed metal oxides show a tendency to form agglomerates held by weaker van der Waals forces. ${ }^{34}$ The microparticle size distributions of selected binary metal oxides were determined from SEM and are shown in Fig. 6. The EDS analysis of the element composition for each metal oxide is exhibited together with the corresponding particle size distribution.

Table 3 Composition and size characteristics of metal oxides

\begin{tabular}{lccc}
\hline Metal oxide type & $\begin{array}{l}\text { Minimum } \\
(\mathrm{nm})\end{array}$ & $\begin{array}{l}\text { Maximum } \\
(\mathrm{nm})\end{array}$ & $\begin{array}{l}\text { Average } \\
\text { size } \pm \text { S.D. }(\mathrm{nm})\end{array}$ \\
\hline $\mathrm{TiO}_{2}$ & 20.4 & 75.1 & $41.5 \pm 16.5$ \\
$\mathrm{TiO}_{2}(50 \%)-\mathrm{ZrO}_{2}(50 \%)$ & 24.3 & 187.8 & $85.3 \pm 45.7$ \\
$\mathrm{TiO}_{2}(33 \%)-\mathrm{ZrO}_{2}(67 \%)$ & 23.7 & 175.0 & $109.0 \pm 57.1$ \\
$\mathrm{ZrO}_{2}$ & 4.4 & 11.6 & $7.9 \pm 2.3$
\end{tabular}
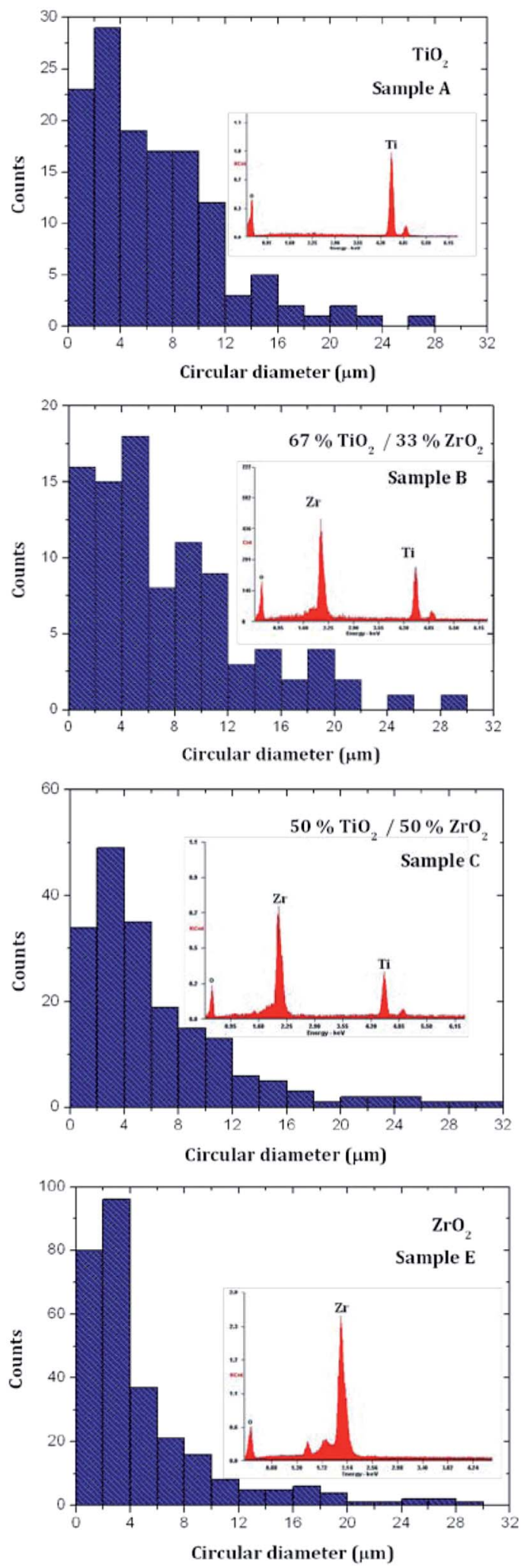

Fig. 6 Particle size distribution of synthesized metal oxides: powder $\mathrm{A}-\mathrm{TiO}_{2}$, powder C - $\mathrm{TiO}_{2}(50 \%)-\mathrm{ZrO}_{2}(50 \%)$, powder D $\mathrm{TiO}_{2}(33 \%)-\mathrm{ZrO}_{2}(67 \%)$ and powder $\mathrm{E}-\mathrm{ZrO}_{2}$.

The metal oxides $\mathrm{TiO}_{2}$ and $\mathrm{ZrO}_{2}$ form aggregates in micron sizes with an average particle size of around $3 \mu \mathrm{m}$. In particular, the prepared $\mathrm{ZrO}_{2}$ oxides are monodisperse aggregates, 
exhibiting a narrow particle size distribution, with a peak at 3 $\mu \mathrm{m}$; the average particle size is smaller than the one observed for $\mathrm{TiO}_{2}$ particles. The formation of binary metal oxides increases the particle size, as well as enhancing the dispersivity of formed particle agglomerates. The observed polydispersity for binary metal oxides with a chemical structure type of $\mathrm{Ti}_{(x)} \mathrm{Zr}_{(1-x)} \mathrm{O}_{2}$ can be explained in terms of the increase of the surface area due to the dissimilar nuclei and co-ordination geometry. ${ }^{35}$ Considering the individual distributions of $\mathrm{TiO}_{2}$ and $\mathrm{ZrO}_{2}$ particles, the presence of titanium in their corresponding structures significantly alters the particle morphology. In other words, the addition of $\mathrm{ZrO}_{2}$ can effectively inhibit the excessive crystal growth of $\mathrm{TiO}_{2}$ micro-crystals during thermal processing. ${ }^{\mathbf{1 1}}$

In order to explore the possible changes in the morphology of metal oxides as a result of dispersion in the solvent during the polymeric solution preparation, solid size measurements in the NMP dispersion were accomplished. The obtained particle size distributions (Fig. 7) were comparable to the metal oxide aggregates analyzed previously (Fig. 6). The particle size of metal oxides dispersed in the organic solvent ranged in the micrometric scale.

\subsection{Membrane morphology characterization}

SEM cross-section images of prepared membranes were taken in order to explore possible changes in the inner morphology of membranes as a result of the addition of binary oxides (Fig. 8).

Due to the high solubility of the solvent (NMP) in water and the low polymer content used for membrane synthesis by phase inversion, the resulting PES membranes exhibit a finger-like structure in their cross-section. The control PES membrane exhibits a typical asymmetric cross-sectional structure, consisting of a skin layer as a selective barrier, a thick finger-like sub-layer and a sponge-like bottom layer. It is well-known that the addition of low amounts $(0.5 \mathrm{wt} \%)$ of inorganic fillers to the polymeric solution alters the morphology of the membrane by the formation of macrovoids and reduction of the thickness of the skin layer. ${ }^{33}$ Both effects are observed as a result of $\mathrm{TiO}_{2}$ addition. Moreover, the use of binary oxides $\operatorname{Ti}_{(x)} \mathrm{Zr}_{(1-x)} \mathrm{O}_{2}$ as inorganic filler particles provokes further changes in the membrane morphology. Symmetrical narrow macrovoids are

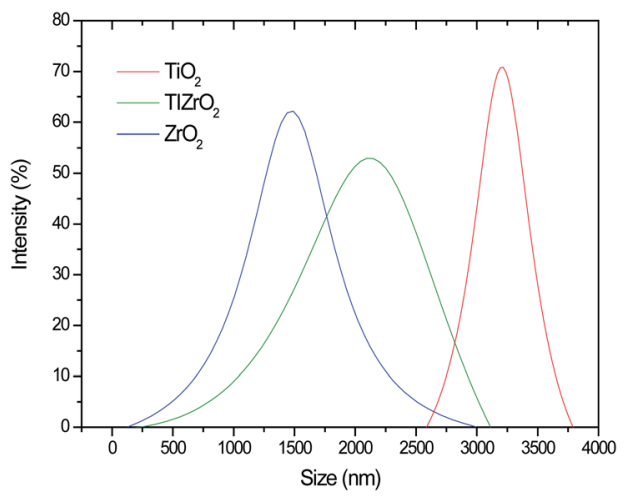

Fig. 7 Metal oxide particle size distribution in NMP
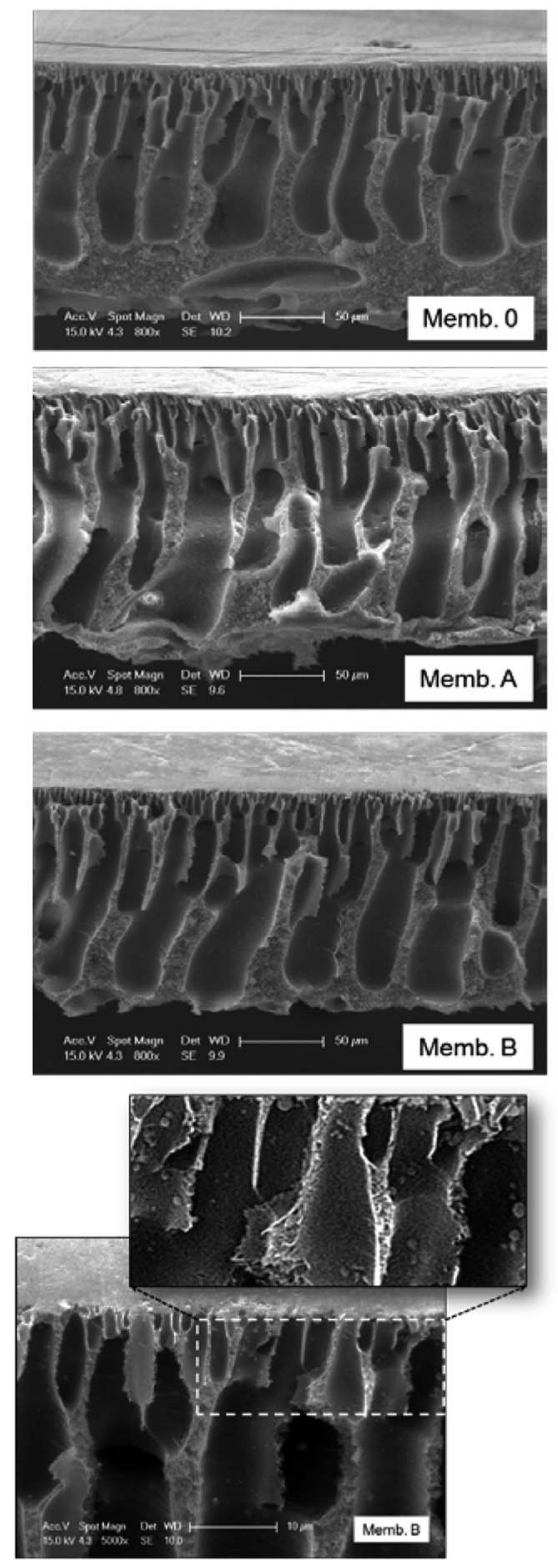

Fig. 8 SEM cross-section images of synthesized membranes at two different magnifications: 800 and 5000×. An additional magnified image of membrane $B$ is shown.

formed, well fixed with the thinner membrane skin layer. The top and bottom sides of the membrane are connected through parallel channels, which can favour water permeation across the membrane. In general, the connectivity of surface pores with the sub-layers is improved after the addition of metal oxide particles.

A magnified image of membrane B is also included in Fig. 8 to allow visualization of metal oxide microparticles inside the membrane structure both in macrovoid walls and in the vicinity of the membrane surface. It is well-known that the hydrophilic character of the nanofiller increases the water transport through the membrane enhancing the membrane water permeation.

The pore size distribution of the membranes is shown in Fig. 9. The average diameters for control and doped membranes 
were 2.5 and $7.5 \mathrm{~nm}$, respectively. As a result of the addition of inorganic particles, the average pore size of the membranes increased to around $5 \mathrm{~nm}$.

The membrane porosity was investigated by two different procedures: from FEG-SEM images (surface pore density) and from uptake water experiments (overall porosity). Calculated values are summarized in Table 4 . Surface porosity in terms of the ratio of pores area to the total membrane surface area yielded small values (lower than $0.5 \%$ ) and are not included in Table 4. The presence of inorganic particles with specific hydrophilic nature enhances the diffusion of the non-solvent (water) into the nascent membrane during the phase inversion process. The favoured water diffusion promotes the formation of lean polymer phase points, which act as pore formation agents. ${ }^{30}$ Both effects, the increase of surface pore density and
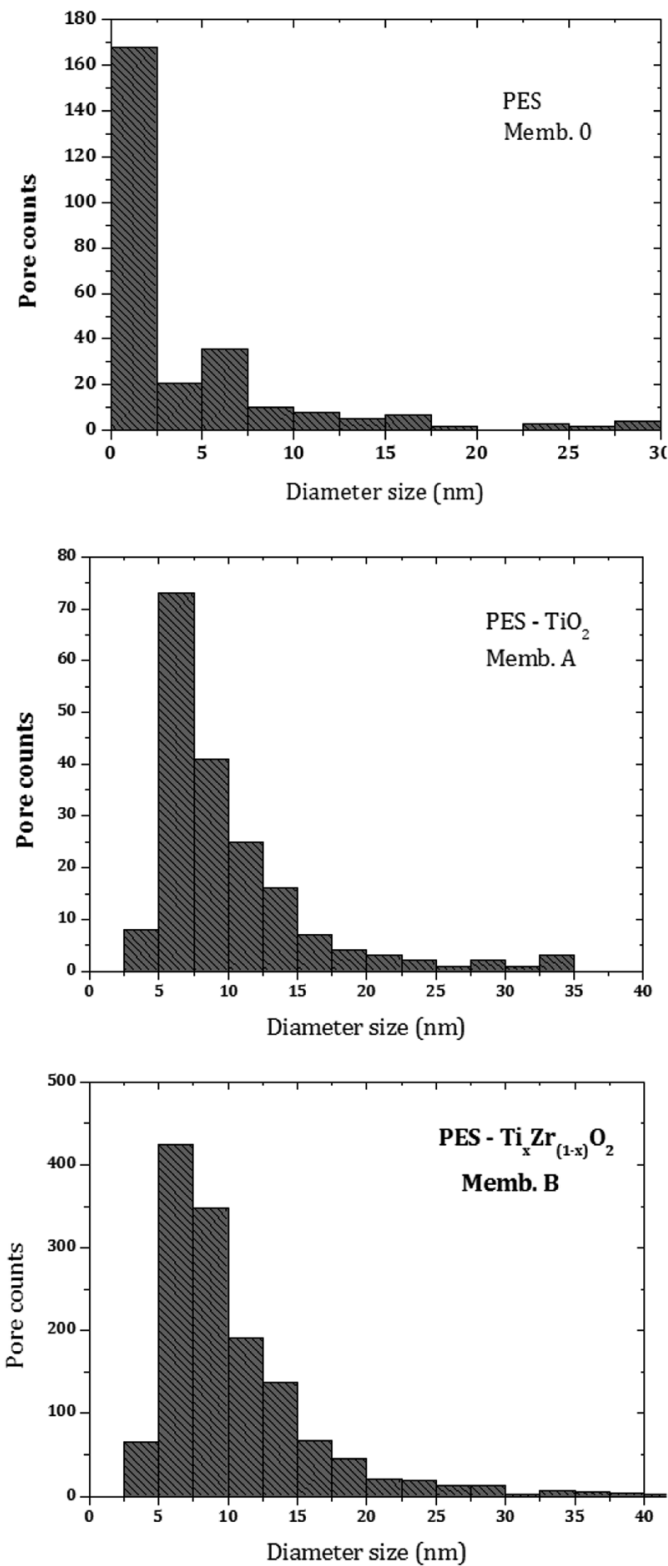

Fig. 9 Pore size distributions of PES control, $\mathrm{PES}-\mathrm{TiO}_{2}$ and PES$\mathrm{Ti}_{x} \mathrm{Zr}_{(1-x)} \mathrm{O}_{2}$ membranes.
Table 4 Values of surface porosity and overall porosity determined by SEM and the water uptake test, respectively, for the control and doped membranes

\begin{tabular}{llcl}
\hline Membrane & $\begin{array}{l}\text { Doping metal } \\
\text { oxide }\end{array}$ & $\begin{array}{l}\text { Surface pore density } \\
\left(\text { pores number } \mu \mathrm{m}^{-2} \text { ) }\right.\end{array}$ & $\begin{array}{l}\text { Porosity } \\
(\%)\end{array}$ \\
\hline Memb. 0 & & 4.35 & 71.26 \\
Memb. A & A & 5.19 & 86.12 \\
Memb. B & B & 21.9 & 90.22 \\
Memb. C & C & 17.2 & 89.08 \\
Memb. D & D & 4.92 & 86.46 \\
Memb. E & E & 4.80 & 83.23
\end{tabular}

the growth of well connected and narrow macrovoids, explain the increasing free-volume in the membrane structure, which favours water sorption inside the membrane. This cooperative effect is evident for Memb. B and Memb. C, both being $\mathrm{Ti}_{(x)} \mathrm{Zr}_{(1-x)} \mathrm{O}_{2}$ modified PES membranes.

The spatial distribution of particles in the membrane crosssection was explored through EDS by collecting the detected signal of chemical elements dispersed inside the membrane structure by X-ray maps (EDAX, USA). The option used for this analysis was EDX fast mapping that provides the capability to acquire X-ray maps at high speed in frame averaging mode. The acquisition parameters to select were: magnification $1000 \times$, numbers of point select for the scan in $x$ and $y$ axis directions for mapping (matrix $256 \times 200$ ), resolutions in both directions $0.513 \times 0.513 \mu \mathrm{m}$ per pixel and the microscope operating at $20 \mathrm{keV}$.

The metal oxide pattern distributions inside the membrane structure obtained from EDS are exhibited in Fig. 10. As shown, pure $\mathrm{TiO}_{2}$ is evenly distributed through the membrane crosssection, in contrast to the pure $\mathrm{ZrO}_{2}$ pattern distribution that reveals that particle density is poor near the skin membrane layer. In addition, Fig. 10 demonstrates that microparticles are present in the membrane top layer whenever the metal oxide contains Ti.

\subsection{Hydrophilicity and water permeation of prepared membranes}

To evaluate the surface hydrophilicity of the membranes doped with different types of metal oxides, surface contact angles were measured (Fig. 11A). It was observed that the contact angle of PES membranes decreases with the incorporation of inorganic fillers, especially for membranes doped with binary metal oxides. In general, the large amount of hydroxyl groups on the surface of metal oxide fillers increases the hydrophilic character of the polymeric material, hydrogen bonds between water and the membrane surface. In the case of metal oxide doped membranes, the observed decrease of contact angles may be related to an increase of the surface pore size. As the dimensions of membrane surface pores increase, more water is adsorbed by the membrane during the contact angle experiments.

Water permeation of synthesized membranes was tested for pure water (Milli-Q), as shown in Fig. 11B. All the doped 

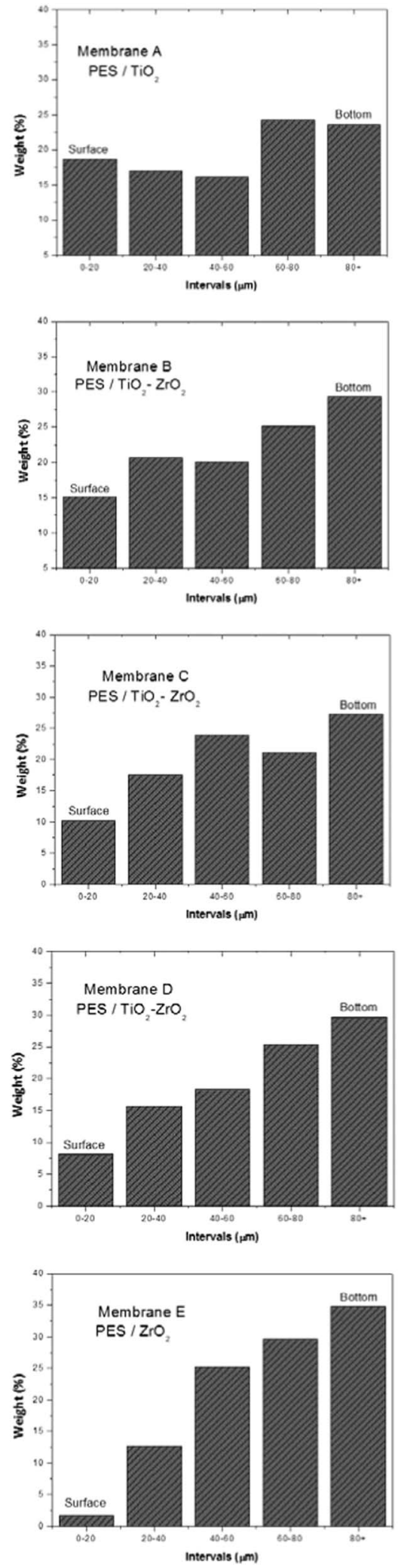

Fig. 10 Metal oxide particle depth distribution from top to bottom in doped membranes.

membranes had a higher pure water flux than the control PES membrane, whereas the maximum fluxes were obtained for membranes doped with metal binary oxides. This is coherent
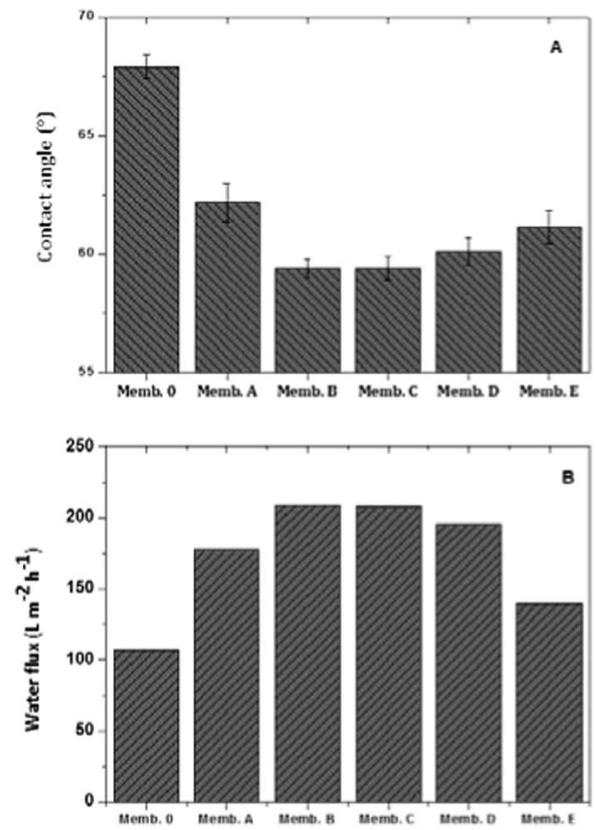

Fig. 11 Hydrophilicity and permeation of manufactured membranes.

with the observed increase of the hydrophilic character of the doped membranes. The higher flux obtained for these membranes can be further related to the increased surface pore density (Table 4) and improved connectivity of inner layers in the morphology (Fig. 8) of metal binary oxides. As the interconnectivity between the sub-layers of the membrane increases with an increased number of surface pores of the skin layer, the membrane hydraulic resistance decreases, resulting in a higher water flux. So, there are three reasons that explain why the flux increases: increased hydrophilicity, surface pore density and pore connectivity.

\subsection{Membrane fouling study}

In order to explore the fouling behavior of the membranes synthesized in this investigation, a model solution of BSA was used to study the flux and protein rejection of control PES and doped membranes (Fig. 12).

The incorporation of metal oxide particles into the polymer matrix caused a significant increase of the membrane flux. The PES-binary oxide doped membrane, Memb. B, had a $48 \%$ higher flux compared to the control PES membrane. Fig. 12 also compares the steady state fluxes.

In order to explore the effect of fouling on the BSA rejection, the observed rejections for each membrane are also shown in Fig. 12B. It can be seen that the rejection of the doped membranes is hardly affected by the incorporation of metal oxide fillers.

The impact of membrane modification on the membrane fouling performance was quantitatively studied using the resistance-in-series mode ${ }^{32}$ as shown in Fig. 13.

The effect of metal oxides addition can be studied from the observed differences between intrinsic membrane resistances obtained for control and doped membranes. In addition, 

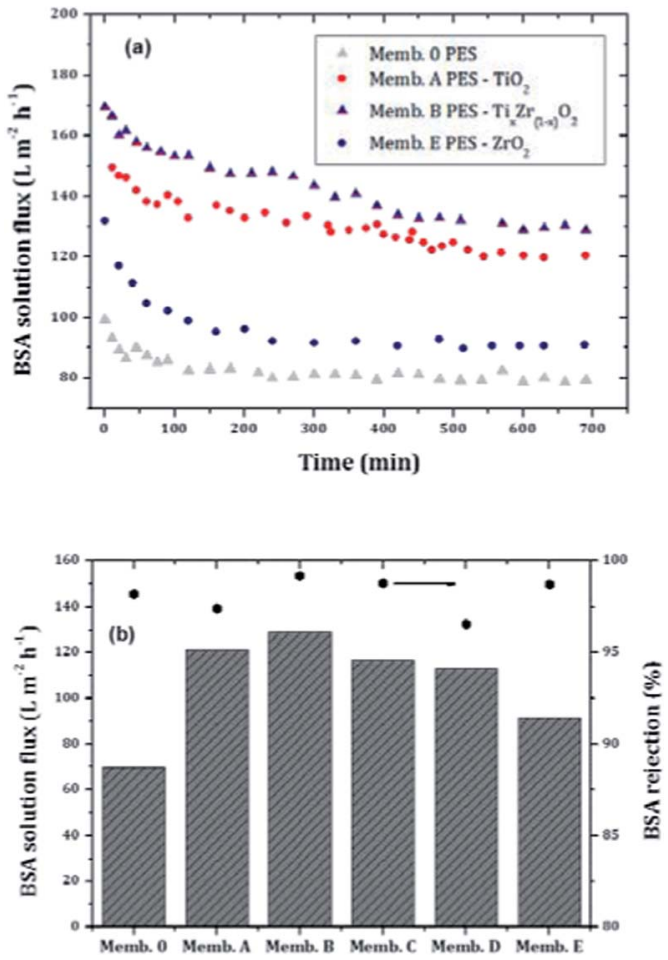

Fig. 12 Temporal evolution of protein solution flux and comparison of BSA solution flux with protein rejection of tested membranes.
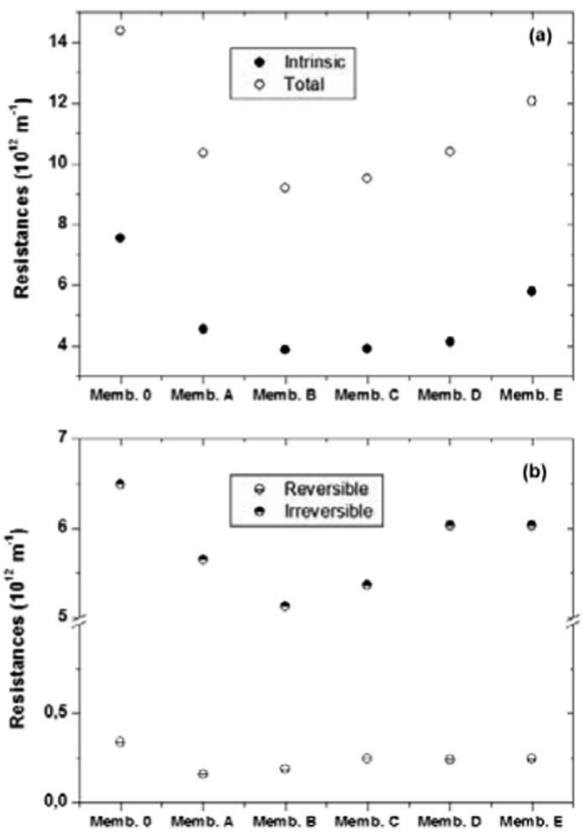

Fig. 13 Filtration resistances of control and doped membranes (a) intrinsic and total resistances (b) reversible and irreversible resistances.

fouling resistance caused by solute adsorption of foulants on the membrane pore wall or surface decreases for the modified membranes, especially for Memb. 2 and Memb. 3. In general, the fouling performance is dominated by the hydrophilic nature of the membrane. The control PES membrane has the highest total and irreversible resistance due to its lower hydrophilicity (Fig. 11A). However, the addition of metal oxides does not have a larger impact on the reversible fouling of membranes. This similar performance in reversible fouling can be caused by the low number of particles distributed at the membrane and pore surfaces, which is a disadvantage for the improvement of the membrane performance. The main difference in fouling resistance of the membranes was observed to be irreversible fouling. However, the irreversible resistance tracks closely with intrinsic resistance, suggesting that the main observed improvement is rather associated with the flux increment.

\section{Conclusions}

The presence of $\mathrm{Ti}$ in the binary oxides $\mathrm{Ti}_{(x)} \mathrm{Zr}_{(1-x)} \mathrm{O}_{2}$ promotes an increase of the size and particle dispersity of synthesized particles. As expected, a gradual increase (blue shift) in the band gap was observed with an increase in the $\mathrm{Zr}$ loading, which indicates potential for photocatalytic applications. Distinct distributions in the membrane structure were found for Ti and $\mathrm{Zr}$ in the metal oxide doped membranes. Particles with $\mathrm{Ti}$ contents are more uniformly dispersed through the membrane cross-section, whereas $\mathrm{Zr}$ oxides are rather present in the middle and near the bottom side of the membrane. The morphology of the binary oxide doped membranes is significantly changed. The pore size, surface and overall porosities of the membranes increase. The surface porosity significantly depends on the particles present in the vicinity of the surface. A specific effect due to the presence of Ti was observed as a consequence of its preferred distribution near the upper membrane layer. The performance of the membranes confirms the potential for application of binary oxides as nanofillers for mixed matrix membranes, taking the observed improvement in flux and anti-fouling properties of doped membranes into account.

\section{Acknowledgements}

The authors are grateful for financial support from the research project "REMTAVARES S2009/AMB/1588" (2010-2013). This research was also supported by Basic Science Research Program through the National Research Foundation of Korea (NRF) funded by the Ministry of Science, ICT and Future Planning (2012R1A1A1011929). The authors gratefully acknowledge María Salud López for supporting the ICP measurements.

\section{References}

1 S. Dogruel, E. U. Cokgor and O. Ince, Environ. Sci. Pollut. Res., 2013, 20, 340.

2 M. S. Araki, C. M. Coutinho, L. A. G. Gon and L. A. Viotto, Sep. Purif. Technol., 2010, 71, 13.

3 J. Lindau and A.-S. Jönsson, J. Membr. Sci., 1999, 160, 65.

4 Y. Zhao, L. Song and L. S. Ong, J. Membr. Sci., 2010, 349, 75.

5 J. M. Arsuaga, A. Sotto, M. J. Lopez-Muñoz and L. Braeken, J. Membr. Sci., 2011, 372, 380. 
6 L. Braeken, K. Boussu, B. Van der Bruggen and C. Vandecasteele, ChemPhysChem, 2005, 6, 1606.

7 J. Kim and B. Van der Bruggen, Environ. Pollut., 2010, 158, 2335.

8 A. Razmjou, J. Mansouri and V. Chen, J. Membr. Sci., 2011, 378, 73.

9 S.-Y. Kawak, S. Kim and S. S. Kim, Environ. Sci. Technol., 2001, 35, 2388.

10 Ng. Yong, N. Wahab, M. A. Leo and C. Peng, Desalination, 2013, 308, 15.

11 A. Sotto, A. Boromand, S. Balta, J. Kim and B. Van der Bruggen, J. Mater. Chem., 2011, 21, 10311.

12 S. Yu, X. Zuo, R. Bao, X. Xu, J. Wang and J. Xu, Polymer, 2009, 50, 553.

13 J. Shen, H. Ruan, L. Ç Wu and C. Gao, Chem. Eng. J., 2011, $168,1272$.

14 D. Parisa, S. S. Madaeni and N. Ghaemi, Sep. Purif. Technol., 2013, 104, 32.

15 M. L. Lind, A. K. Ghosh, A. Jawor, X. Huang, W. Hou, Y. Yang and E. M. V. Hoek, Langmuir, 2009, 25, 10139.

16 M. Muhlmann, A. Magerl and W. A. Goedel, Langmuir, 2012, 28, 8197.

17 X.-M. Wang, X.-Y. Li and K. Shih, J. Membr. Sci., 2011, 368, 134.

18 Y. Q. Deng, G. D. Dang, H. W. Zhou, X. H. Rao and C. H. Chen, Mater. Lett., 2008, 62, 1143.

19 G. Arthanareeswaran and P. Thanikaivelan, Sep. Purif. Technol., 2010, 74, 230-235.

20 S. Balta, A. Sotto, P. Luis, L. Benea, B. Van der Bruggen and J. Kim, J. Membr. Sci., 2012, 389, 155.

21 S. Xiao, M. Shen, R. Guo, S. Wang and X. Shi, J. Phys. Chem. $C, 2009,113,18062$.

22 L. D. Nghiem, A. Schäfer and M. Elimelech, Environ. Sci. Technol., 2004, 38, 1888.

23 R. S. Mane, W. J. Lee, H. M. Pathan and S.-H. Han, J. Phys. Chem. B, 2005, 109, 24254.

24 M. A. Ahmad, B. Prelot and F. Dufour, J. Phys. Chem. C, 2013, 117, 4459.

25 S. Kang, A. Asatekin, A. M. Mayes and M. Elimelech, J. Membr. Sci., 2007, 296, 42.
26 S. Liang, Y. Kang, A. Tiraferri, E. Giannelis, X. Huang and M. Elimelech, ACS Appl. Mater. Interfaces, 2013, 5, 6694.

27 R. Saranya, G. Arthanareeswaran, S. Sakthivelu and P. Manohar, Ind. Eng. Chem. Res., 2012, 51, 4942.

28 Y. Yang, H. Zhang, P. Wang, Q. Zheng and J. Li, J. Membr. Sci., 2007, 288, 231.

29 N. A. Hamid, A. F. Ismail, T. Matsuura, A. W. Zularisam, W. J. Lau, E. Yuliwati and M. S. Abdullah, Desalination, 2011, 273, 85.

30 N. Maximous, G. Nakhla, W. Wan and K. Wong, J. Membr. Sci., 2009, 341, 67.

31 N. Maximous, G. Nakhla, W. Wan and K. Wong, J. Membr. Sci., 2010, 352, 220.

32 A. Sotto, A. Boromand, R. Zhang, P. Luis, J. M. Arsuaga, J. Kim and B. Van der Bruggen, J. Colloid Interface Sci., 2011, 363, 540.

33 J. M. Arsuaga, A. Sotto, G. del Rosario, A. Martínez, S. Molina, S. B. Teli and J. de Abajo, J. Membr. Sci., 2013, 428, 131.

34 J. J. Jiang, G. Oberdorster and P. Biswas, J. Nanopart. Res., 2009, 11, 77.

35 C. Wu, X. Zhao, Y. Ren, Y. Yue, W. Hua, Y. Cao, Y. Tang and Z. Gao, J. Mol. Catal. A: Chem., 2005, 229, 233.

36 T. Sato, J. Therm. Anal., 2002, 69, 255.

37 U. Troitzsch and J. Ellis, J. Mater. Sci., 2005, 40, 4571.

38 A. Bianco, G. Gusmano, R. Freer and P. Smith, J. Eur. Ceram. Soc., 1999, 19, 959.

39 U. Troitzsch, A. G. Christy and J. Ellis, J. Am. Ceram. Soc., 2004, 87, 2058.

40 X. Fu, L. A. Clark, Q. Yang and M. A. Anderson, Environ. Sci. Technol., 1996, 30, 647.

41 X. Wang, J. C. Yu, Y. Chen, L. Wu and X. Fu, Environ. Sci. Technol., 2006, 40, 2369.

42 B. Neppolian, Q. Wang, H. Yamashita and H. Choi, Appl. Catal., A, 2007, 333, 264.

43 J. B. Cohen, Diffraction Methods in Materials Science, The Macmillan Comp., New York, 1966.

44 Crystallography Open Database (COD): http://www. crystallography.net/. 